\title{
ANALISIS KUALITATIF KANDUNGAN BAHAN KIMIA OBAT PREDNISON PADA JAMU REMATIK DAN PEGAL LINU DI DAERAH KARAWANG BARAT
}

\author{
Lia Fikayuniar* ${ }_{2}$ Ermi Abriyani
}

Fakultas Farmasi, Universitas Buana Perjuangan Karawang, Karawang, Jawa Barat, Indonesia.

*Penulis Korespondensi: lia.fikayuniar@ubpkarawang.ac.id

\begin{abstract}
ABSTRAK
Semakin maraknya penggunaan obat tradisional berdasarkan khasiat yang turun temurun, semakin memperluas kesempatan terjadinya pemalsuan simplisia, bahkan ada beberapa jamu yang mengandung Bahan Kimia Obat (BKO) yang telah jelas dilarang penambahannya, baik sengaja maupun tidak disengaja ke dalam obat tradisional. Tujuan dari penelitian ini adalah untuk mengidentifikasi kandungan Bahan Kimia Obat (BKO) prednison pada jamu rematik dan pegal linu. Sampel jamu yang digunakan yaitu sebanyak sepuluh sampel jamu yang berbeda dengan metode Kromatografi Lapis Tipis (KLT) sebagai metode kualitatif. Hasil penelitian ini menunjukan adanya lima sampel jamu (yang positif mengandung Bahan Kimia Obat (BKO) yang dianalisis dengan eluen etil asetat - kloroform dengan masing masing pebandingan 6:4 dan 8:2 sampel (A, B, C, E, dan J), 9:1 (A,B, C,E, F), dengan Rf yang sama dengan baku standar (prednisone p.a) dan memilik warna bercak biru-ungu.
\end{abstract}

Kata kunci: Bahan Kimia Obat, Jamu, Karawang, Prednison, Kromatografi Lapis Tipis 


\title{
QUALITATIVE ANALYSIS OF THE CONTENT OF PREDNISONE CHEMICALS IN RHEUMATISM HERB AND ACHING PAINS HERBS \\ IN THE WEST KARAWANG REGION
}

\begin{abstract}
The increasing use of traditional medicines based on hereditary properties, the more opportunities for simplicia forgery, there are even some herbs that contain medicinal chemicals (BKO) which prohibited from adding them, either intentionally or accidentally, to traditional medicines. The purpose of this study was to identify the content of medicinal chemicals (BKO) prednisone in rheumatic herbs and stiff rheumatism. The sample used was ten different herbal samples with Thin Layer Chromatography (TLC) as a qualitative method. The results of this study showed that there were five samples of Jammu (positive for containing medicinal chemicals (BKO) which analyzed with ethyl acetate eluent-chlorofm with comparisons of (6:4 and 8:2) samples respectively (A, B, C, E, and J), 9: 1 (A, B, C, E, F), where the Rf is the same as the standard (prednisone p.a) and has a blue-purple patch colour.
\end{abstract}

Keywords: Contain Medicinal Chemical, Herbs, Karawang, Prednisone, Thin-layer Chromatography

\section{PENDAHULUAN}

Jamu merupakan salah satu obat bahan alam Indonesia dengan presentase konsumen sebanyak 59,12\%. Cukup tingginya presentase masyarakat yang menggunakan jamu karena dinilai memiliki efek samping yang relatif lebih sedikit apabila aspek keamanannya terpenuhi. Semakin maraknya penggunaan obat tradisional berdasarkan khasiat yang turun temurun, semakin memperluas kesempatan terjadinya pemalsuan simplisia, bahkan ada beberapa jamu yang mengandung Bahan Kimia Obat (BKO) yang telah jelas dilarang penambahannya, baik sengaja maupun tidak disengaja ke dalam obat tradisional, seperti yang tertera pada Peraturan Menteri

Kesehatan No. 246/Menkes/Per/V/1990

BAB V Pasal 23 (Fauziah et al., 2015).

Prednison dosis tinggi atau jangka panjang beresiko mengalami keropos tulang. Keropos tulang mungkin merupakan efek samping pengobatan steroid yang paling serius. Pada orangorang yang menerima prednison dengan dosis harian sebesar 7,5 mg atau lebih, resiko patah ruas tulang belakang lima kali lebih tinggi ketimbang orang-orang yang tidak menerima steroid (Cosman, 2011).

Berdasarkan uraian di atas, maka akan dilakukan analisis kualitatif kandungan bahan kimia obat prednison pada jamu rematik dan pegal linu di 
daerah karawang barat, sehingga dapat digunakan sebagai referensi bagi masyarakat tentang keamanan dari beberapa sediaan jamu rematik yang beredar di pasaran.

\section{METODE PENELITIAN}

\section{Pengumpulan Sampel Jamu}

Sampel jamu pegal linu dan rematik diambil di toko jamu di daerah kota karawang. Total sampel yang digunakan adalah sepuluh jenis jamu dengan berbagai merk yang berbeda.

\section{Kromatografi Lapis Tipis}

\section{a. Pembuatan fase gerak}

Etil asetat di campurkan dengan kloroform dengan pemilihan perbandingan yang tepat yaitu (6:4), (8:2), (9:1) pada chamber yang telah disediakan sesuai dengan perbandingan eluen tersebut.

b. Pembuatan larutan baku pembanding

Prednison 100 ppm ditimbang kemudian di masukan ke dalam labu ukur $25 \mathrm{ml}$, dan di tambahkan etanol sampai tanda batas aduk homogen.

\section{c. Pembuatan larutan sampel}

Sampel jamu ditimbang $500 \mathrm{mg}$ lalu dimasukkan ke dalam labu ukur tambahkan etanol aduk sampai homogen kemudian disonikasi dengan sonikator selama 20 menit saring dan tampung, uapkan dengan cara diangin-anginkan larutan hingga terbentuk ekstrak etanol kental.

\section{d. Identifikasi kromatografi lapis} tipis

Larutan sampel jamu dan larutan baku pembanding Prednison ditotolkan pada lempeng KLT, dimasukkan ke dalam chamber yang berisi eluen kloroform-etil asetat. Setelah eluen mencapai batas tanda, angkat plat KLT dan keringkan. Kemudian kromatogram yang dihasilkan diamati nodanya di bawah lampu sinar ultra violet (UV) pada panjang gelombang $254 \mathrm{~nm}$. Amati ada tidaknya kesamaan pada penampakan noda dan hitung nilai Rf-nya dan sampel dibandingkan dengan nilai Rf serta warna bercak baku pembanding prednison.

\section{e. Analisis data}

Analisa data yang digunakan pada penelitian ini secara kualitatif, dengan analisis deteksi kromatrografi lapis tipis, dengan mengamati hasil bercak dibawah sinar lampu UV pada panjang gelombang $254 \mathrm{~nm}$. Setelah itu, bercak yang didapatkan diberi tanda dan dan dihitung $\mathrm{Rf}$ (Retardation factor). Nilai Rf tersebut dibandingkan dengan nilai $\mathrm{Rf}$ baku 
pembanding (kontrol positif),

bercak yang dimaksud adalah

bercak yang memiliki warna sama

dengan baku pembanding. Faktor

retardasi solut (Rf) dapat didefinisikan dengan perhitungan berikut:

$$
R f=\frac{\text { Jarak yang ditempuh solut }}{\text { Jarak yang ditempuh fase gerak }}
$$

\section{HASIL PENELITIAN}

Hasil Uji Kromatografi Lapis Tipis

a. Perbandingan eluen etil asetat-kloroform (6:4)

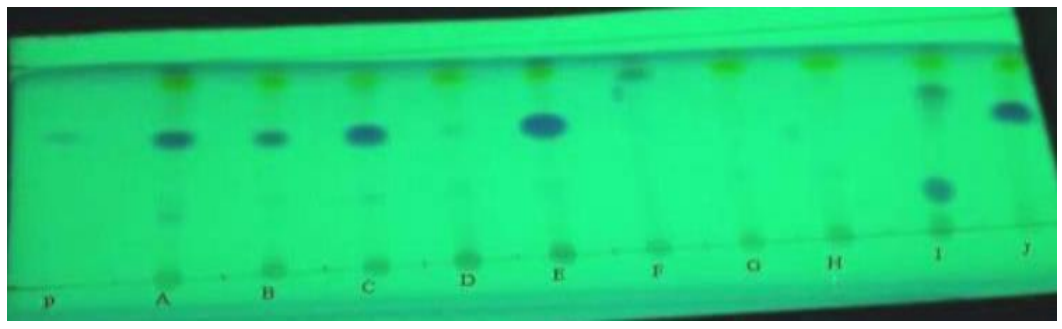

Gambar 1. Hasil kromatogram KLT pada sampel dan prednison p.a dengan menggunakan perbandingan eluen etil setat-kloroform (6:4).

Tabel 1. Hasil perhitungan Rf sampel dengan prednison p.a dengan menggunakan eluen etil asetat-kloroform (6:4)

\begin{tabular}{cccc}
\hline Sampel & Nilai Rf Baku Standar Prednison & Nilai Rf Sampel & Keterangan \\
\hline A & 0,69 & 0,69 & Positif \\
B & 0,69 & 0,69 & Positif \\
C & 0,69 & 0,69 & Positif \\
D & 0,69 & 0,80 & Negatif \\
E & 0,69 & 0,69 & Positif \\
F & 0,69 & 0,31 & Negatif \\
G & 0,69 & 0,31 & Negatif \\
H & 0,69 & 0,20 & Negatif \\
I & 0,69 & 0,66 & Negatif \\
J & 0,69 & 0,69 & Positif \\
\hline
\end{tabular}


b. Perbandingan eluen etil asetat-kloroform (9:1)

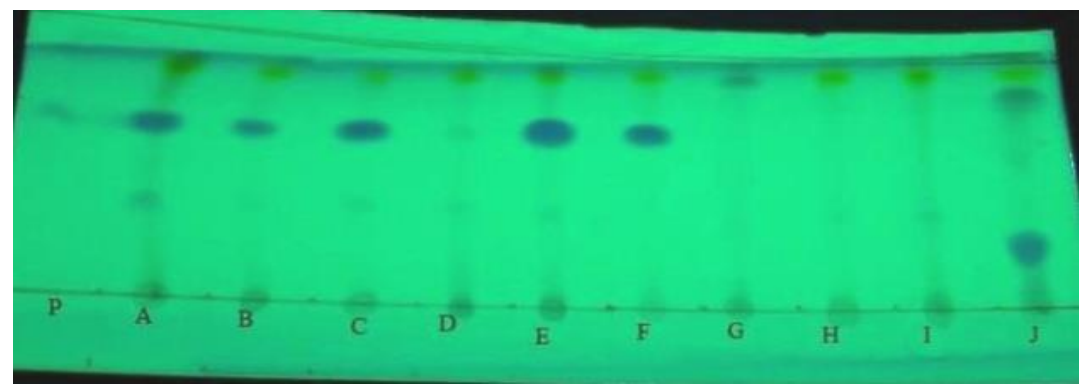

Gambar 2. Hasil kromatogram KLT pada sampel dan prednison p.a dengan menggunakan

perbandingan eluen etil asetat-kloroform (9:1).

Tabel 2. Hasil perhitungan Rf sampel dengan prednison p.a dengan menggunakan eluen etil asetat-kloroform (9:1)

\begin{tabular}{cccc}
\hline Sampel & Nilai Rf Baku Pembanding & Nilai Rf Sampel & Keterangan \\
\hline A & 0,66 & 0,66 & Positif \\
B & 0,66 & 0,66 & Positif \\
C & 0,66 & 0,66 & Positif \\
D & 0,66 & 0,66 & Positif \\
E & 0,66 & 0,66 & Positif \\
F & 0,66 & 0,66 & Positif \\
G & 0,66 & 0,94 & Negatif \\
H & 0,66 & 0,40 & Negatif \\
I & 0,66 & 0,40 & Negatif \\
J & 0,66 & 0,23 & Negatif \\
\hline
\end{tabular}

c. Perbandingan eluen etil asetat-kloroform (8:2)

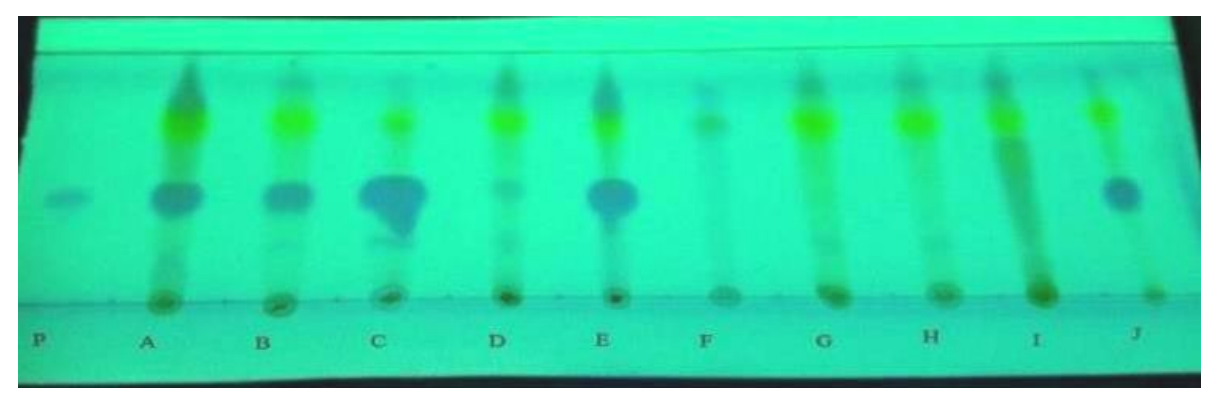

Gambar 3. Hasil kromatogram KLT pada sampel dan prednison p.a dengan menggunakan perbandingan eluen etil asetat-kloroform (8:2). 
Tabel 3. Hasil perhitungan $\mathrm{Rf}$ sampel dengan prednison p.a dengan menggunakan eluen etil asetat-kloroform $(8: 2)$

\begin{tabular}{cccc}
\hline Sampel & Nilai Rf Baku Pembanding & Nilai Rf Sampel & Keterangan \\
\hline A & 0,40 & 0,40 & Positif \\
B & 0,40 & 0,40 & Positif \\
C & 0,40 & 0,40 & Positif \\
D & 0,40 & 0,23 & Negatif \\
E & 0,40 & 0,40 & Positif \\
F & 0,40 & 0,40 & Positif \\
G & 0,40 & 0,69 & Negatif \\
H & 0,40 & 0,23 & Negatif \\
I & 0,40 & 0,23 & Negatif \\
J & 0,40 & 0,40 & Positif \\
\hline
\end{tabular}

\section{PEMBAHASAN}

Pada Gambar 1. menunjukkan bahwa pada hasil kromatogram hasil uji KLT Pembanding prednison p.a dari BPOM dengan no kontrol 309276 dengan sampel jamu A-J dengan perbandingan eluen etil asetat-kloroform (6:4) sampel jamu A, B, C, E dan J memiliki warna yang sama dengan baku standar yaitu memiliki warna bercak biru-ungu yang berflouresensi dibawah lampu sinar ultra violet pada panjang gelombang $254 \mathrm{~nm}$ dan sama-sama memiliki nilai $\mathrm{Rf}$ yang sama dengan baku standar itu arti nya lima sampel tersebut positif mengandung prednison (Wirastuti et al., 2016).

Pada Tabel 1. menunjukkan hasil pengujian pertama yaitu pengujian kualitatif menggunakan metode kromatografi lapis tipis (KLT) dengan perbandingan eluen etil asetat-kloroform (6:4) didapatkan nilai $\mathrm{Rf}$ untuk pembanding prednison 0,69 untuk sampel jamu A, B, C, E dan J memiliki nilai Rf yang sama dengan baku standar yaitu 0,69 , berarti sampel tersebut megandung prednison (positif), sedangkan untuk smpel jamu D, F, G, H, dan I memiliki nilai Rf yang berbeda dengan pembanding yang artinya sampel tersebut tidak mengandung prednison (negatif).

Pada Gambar 2. menunjukkan bahwa pada hasil kromatogram hasil uji KLT baku standar prednison p.a dari BPOM dengan no kontrol 309276 dengan sampel jamu A-J dengan perbandingan eluen etil asetat-kloroform (9:1) sampel jamu A, B, C, E dan F memiliki warna yang positif dengan baku standar yaitu dan memiliki warna bercak biru-ungu dibawah lampu sinar ultra violet pada panjang gelombang $254 \mathrm{~nm}$ dan samasama memiliki nilai $\mathrm{Rf}$ yang sama dengan baku standar itu arti nya positif mengandung prednison (Wirastuti et al., 2016). 
Pada Tabel 2. pengujian kedua pada metode yang sama namun menggunakan perbandingan eluen etil asetat-kloroform yang berbeda yaitu 9:1 didapatkan nilai $\mathrm{Rf}$ untuk pembanding prednison yaitu 0,66 untuk sampel jamu A, B, C, E dan F memiliki nilai $\mathrm{Rf}$ yang sama dengan pembanding yaitu 0,66 , sedangkan untuk sampel jamu G, H, I dan J memiliki nilai Rf yang berbeda dengan baku standar.

Pada Gambar 3. Menunjukkan bahwa pada hasil kromatogram uji KLT Pembanding prednison p.a dari BPOM dengan no kontrol 309276 dengan sampel jamu A-J, sampel jamu a, b, c, e dan j dengan mengunakan eluen etil asetatkloroform (8:2), memiliki warna yang positif dengan pembanding yaitu memiliki warna noda biru-ungu dibawah lampu sinar ultra violet pada panjang gelombang $254 \mathrm{~nm}$ dan sama-sama memiliki nilai $\mathrm{Rf}$ yang sama dengan pembanding dan itu arti nya positif mengandung prednison (Wirastuti et al., 2016).

Pada Tabel 3. menunjukkan pengujian ketiga dengan metode kromatografi lapis tipis dengan menggunakan perbandingan eluen etil astetat-kloform (8:2) didapatkan nilai $\mathrm{Rf}$ 0,40 untuk pembanding dan sampel A, B, C, E dan $\mathrm{J}$ ini dapat diartikan sampel tersebut postif mengandung prednison, sedangkan untuk sampel D, F, G, H, dan I memiliki nilai $\mathrm{Rf}$ yang berbeda dengan baku standar. Dari sepuluh sampel jamu yang telah diidentifikasi secara kualitatif dengan melihat hasil dari Rf kromatografi lapis tipis, dan warna yang dihasilkan positif atau negatif mengandung bahan kimia obat, berdasarkan peraturan perudang-undangan yang berlaku, obat tradisional dilarang menggunakan bahan kimia hasil isolasi atau sintetik berkhasiat obat, Narkotik atau pasikotropik, hewan atau tumbuhan yang dilindungi (BPOM, 2020), salah satu nya adalah tidak boleh mengandung bahan kimia obat. Pada sampel yang diindetifikasi ternyata positf mengandung prednison. Prednison ini yang merupakan obat golongan steroid yang banyak digunakan untuk ditambahkan pada jamu penyakit rematik, asma, pegal linu. Dan yang menjadi bahaya ketika bahan kimia obat ini ditambahkan pada jamu adalah tidak diketahui besar nya dosis dan lama pemakaiannya, maka akan mengakibatkan osteoporosis jika dikonsumsi (Wirastuti et al., 2016). Penelitain yang telah dilakuakn pada semua sampel jamu telah di telusuri belum ada terdeteksi pada informasi e-BPOM.

\section{KESIMPULAN}

Berdasarkan hasil penelitian, dapat disimpulkan bahwa hasil identifikasi dengan metode kualitatif menggunakan 
metode KLT dari sampel jamu A, B, C, $\mathrm{D}, \mathrm{E}, \mathrm{F}$ dan $\mathrm{J}$ yang menunjukkan positif mengandung prednison dengan eluen etil asetat-kloroform (6:4 dan 8:2) yaitu pada sampel A, B, C, E, dan J, sedangkan pada perbandingan (9:1) adalah sampel A, B, C, E, dan F, sedangkan untuk sampel jamu D, G, H dan I tidak mengandung bahan kimia obat $(\mathrm{BKO})$ prednison.

\section{DAFTAR PUSTAKA}

Cosman, F. 2011. Osteoporosis. Yogyakarta: Panduan Kesehatan Wanita.
Fauziah, SS., Lestari, F., Lukmayani, Y., dan Aprilia H. Pengaruh Pemberian Jamu Pegal Linu Mengandung Bahan Kimia Obat (BKO) Terhadap Fungsi Hati Tikus Wistar Jantan. Prosiding Penelitian SPeSIA Unisba, 2015, 96-103.

https://www.pom.go.id/new/view/more/b erita/144/BAHAYA-BAHANKIMIA-OBAT--BKO--YANGDIBUBUHKAN-KEDALAMOBAT-TRADISIONAL--JAMU.html (Diakses pada tanggal 15 Agustus 2020).

Wirastuti, A., Dahlia, AA dan Najib, A. Pemeriksaan Kandungan Bahan Kimia Obat (BKO) Prednison Pada Beberapa Sediaan Jamu Rematik. Jurnal Fitofarmaka Indonesia, 2016, 3(1). 